\title{
Are There Relationships Among Racial Segregation, Economic Isolation, and Proximity to Green Space?
}

\author{
Salvatore Saporito' \\ Department of Sociology, College of William \& Mary \\ Williamsburg, Virginia, United States \\ Daniel Casey \\ Institute for Health Metrics and Evaluation \\ University of Washington, Seattle, United States
}

\section{Abstract}

Prior research has investigated differences in exposure to green space between racial and economic groups across the United States. Results have generally shown that people of color and lower-income groups tend to live in neighborhoods with less green space than their more-advantaged counterparts. Our research extends existing studies by measuring the association between racial and economic differences in exposure to green space and racial or economic segregation across neighborhoods within cities. Findings show that cities with lower levels of racial segregation exhibit smaller racial disparities in exposure to green space. By contrast, in cities with greater racial segregation, white people tend to live in neighborhoods with more green space than do people of color. This difference is more pronounced between white and Hispanic people. Finally, there is a strong association between segregation among different income groups and differences in exposure to green space between lower- and higher-income people. Consistent with much of the literature on racial and economic segregation-and studies of environment (in)justice - we find that lower-income people and members of minority groups live in neighborhoods with much less vegetation than their wealthier, white counterparts and these differences are exacerbated in racially and economically segregated cities.

Keywords: economic segregation, green space, racial segregation

$1 \quad$ Corresponding author: sjsapo@wm.edu. 


\section{Are there relationships among racial segregation, economic isolation, and proximity to green space?}

It is well known that racial segregation within a city increases exposure to poverty among members of minority groups (Massey \& Fischer, 2000). Studies have also shown that, in general, minorities and lower-income people live closer to noxious land uses than do white and higher-income people. These social ills include proximity to waste dumps, superfund sites, incinerators, air pollution, traffic (Bullard, 2000; Crowder \& Downey, 2010; Wing et al., 2000), food deserts (Wrigley et al., 2003; Zenk et al., 2005), fast-food chains (Boone-Heinonen et al., 2011; Kwate, 2008), social disorganization, crime, police surveillance and incarceration (Goffman, 2014; Sampson, 2012), and deteriorating and abandoned buildings (Adelman, 2004).

More recently, scholars have expanded their research to include analyses of unequal proximity to social amenities such as playgrounds and recreational facilities (Cradock et al., 2005), banks (Squires \& O'Connor, 1998), and restaurants, grocery stores, coffee houses, movie theaters, and clothing stores (Duncan et al., 2012). In particular, researchers have examined the proximity of different racial and economic groups to green space such as urban parks, street trees, greenways, and tree canopy cover. Urban green space has been identified as an environmental amenity by a variety of scholars and urban planners because it typically has two qualities: the presence of vegetation and social upkeep (Heynen, 2003; Heynen et al., 2006; Landry \& Chakraborty, 2009; Lindsey et al., 2001; Sister et al., 2010; Troy et al., 2007; Wen et al., 2013; Wendel et al., 2011).

As studies of urban tree canopy cover highlight, municipalities often use trees and other vegetation to alter the urban landscape. These alterations take the form of green medians, parks, greenways, and similar features (Heynen et al., 2006; Landry \& Chakraborty, 2009; Lindsey et al., 2001; Wen et al., 2013). In these cases, the presence of green space is not necessarily "natural." Instead, its existence is created and maintained by urban planners, municipal departments of transportation, local environmental groups, and other organizations. Given its social and political foundations, an important question is whether the production and maintenance of green space by municipalities is distributed evenly - particularly when the distribution of racial and economic groups is distributed unevenly.

This is a key question since green space provides numerous benefits, including improving water conservation, reducing carbon dioxide, enhancing air quality, increasing biodiversity, and limiting runoff (Heynen \& Lindsey, 2003; 
Heynen et al., 2006). It is also associated with socioeconomic benefits, including higher property values, greater aesthetics, and social cohesion (Landry \& Chakraborty, 2009). Finally, exposure to greater vegetation and parks has been shown to improve health outcomes by reducing stress and increasing physical exercise (Chiesura, 2004; Maas et al., 2006; Maller et al., 2006; Mitchell \& Popham, 2008; Nielsen \& Hansen, 2007; Ward-Thompson et al., 2012).

Many of these same studies examine the density of green space across neighborhoods that vary in their racial and economic composition. Findings generally show that lower-income people and racial minorities live closer to a patch of green space than white people but live in neighborhoods with lower densities of green space. For example, Landry and Chakraborty (2009) used high-resolution imagery (i.e., one square meter) to determine the density of publicly planted trees on sidewalks and similar public spaces in Tampa, Florida. They found that lower-income people and members of minority groups were exposed to less green space than were higher-income and white people. A case study of Milwaukee showed that the proportion of census tract areas that were covered by tree canopy was negatively correlated with concentrations of lower-income and minority people (Heynen et al., 2006). Still other studies examined the density of green space in the form of public parks and found that, in Philadelphia, non-whites and renters lived near less green space overall than whites and homeowners (Heckert, 2013). Similarly, findings from Baltimore indicate that a higher proportion of African Americans have access to parks within walking distance than whites, but whites have access to more acreage of parks within walking distance than African Americans (Boone et al., 2009). Findings from these intensive cases studies of specific cities have been replicated on a national scale and show that members of disadvantaged groups live closer to green space such as parks but live in census tracts with less green space (Wen et al., 2013).

We add to the existing literature in several ways. First, we use the most recent estimate of vegetative cover based on 2012 satellite imagery. This imagery estimates the intensity of vegetation inside cells of a 30 by 30 meter grid allowing us to generate a reasonably accurate indication of green space within a relatively small area. Second, the grid covers the continental United States. Thus, like case studies of cities, we use relatively high-resolution land cover data to determine vegetative densities but, unlike case studies, our analysis is at a national scale. Third, we use block group data derived from the United States Census Bureau's 2008-2012 American Community Survey; the use of block groups is important since they are a much more reasonable definition of "neighborhood" than are census tracts. Finally - and most importantly - we explore two new questions: First, what is the association between racial segregation across cities and 
differences in the exposure to green space between white and non-white people? Second, what is the correlation between economic segregation across cities and differences in exposure to green space among different economic groups?

By definition, when members of different racial groups live in the same, small neighborhoods they are all equally exposed to grass, shrubs, trees, and other vegetation. However, when advantaged and disadvantaged people live in different neighborhoods within a city it may be that advantaged people live in neighborhoods with higher densities of vegetation than members of disadvantaged groups. Yet, no study has investigated whether racial segregation within a city is associated with greater racial and socioeconomic disparities in exposure to green space. This is an open question since it may be that a variety of factors may mitigate the otherwise deleterious effects of segregation. For example, municipalities with greater racial and economic segregation may try to ensure that all neighborhoods - irrespective of their demographic makeuphave their fair share of greenways, parks, sidewalk trees, and the like. Or it may be that racial minorities and those with lower incomes plant urban gardens in empty lots, seek low-cost housing adjacent to green space, or live outside the urban core. While a cross-sectional study such as ours cannot determine why a link between segregation and green space disparities exist, an important first step is to explore the strength of this association.

\section{Data and measures}

We linked data from several sources. The first was a composite mosaic of Landsat 7 imagery from the 2012 growing season. These data were processed and distributed by a consortium comprising the University of Maryland Department of Geographical Sciences, Google, USGS, and NASA (Hansen et al., 2013). From these data we created "normalized difference vegetation index" (NDVI) values. For some portions of the country, cloud-free satellite imagery for 2012 was not available. In these cases, data from the time frame closest to the 2012 summer was used. Imagery covers the continental United States and is available at a resolution of 30 by 30 meter raster (or grid). ${ }^{2}$

\footnotetext{
2 Although our research question is different from that of Wen et al. (2013), our national study differs from theirs in two other respects. First, they used classified land use data in which every cell in a raster is classified into a single category. Cells that may have had some vegetation may have been classified as "urban" or "residential." Classifying cells into discrete categories may be problematic in urban areas where verdancy likely coexists with other land uses (e.g., pavement, rooftops) within a cell. Our study ensured that verdancy was measured even if it was relatively sparse. Second, we used block groups while they measured neighborhoods using larger areas (i.e., census tracts).
} 
The NDVI score is derived from the proportion of visible light (VIS) and nearinfrared light (NIR) that is absorbed or reflected by plants (and by non-plant matter) on or near the earth's surface. The chlorophyll in vegetation absorbs most VIS with wavelengths between 400 and 700 nanometers. Low proportions of VIS reflected from an area of the earth's surface indicate that the area is covered by dense, living vegetation. When an area is barren of live leaves, most incoming VIS is reflected and values of VIS are close to 1. Higher densities of leaves reflect greater amounts of NIR, at wavelengths around 700-1100 nanometers.

NDVI is calculated by subtracting the proportion of VIS reflected from the earth's surface from the proportion of NIR reflected and dividing this value by the sum of the proportions of NIR and VIS:

$$
N D V I=\left(\frac{N I R-V I S}{N I F+V I S}\right) \times 10,000
$$

We multiplied NDVI scores by 10,000 for ease of reporting. A 30 by 30 meter raster cell with an NDVI value between 2,000 and 4,000 typically indicates the presence of grass, shrubs, and sparse tree cover; such values in urban settings often indicate a park, large garden, golf course, playing field, or streets with trees. Values above 4,000 represent denser tree canopy (with values close to 10,000 indicating rainforests). For example, Seattle, Washington, has parks (e.g., Westcrest and Schmitz) that contain numerous pixels with NDVI values well above 4,000. Values of -10,000 represent water (and these cells are excluded from our calculations).

We took the NDVI scores of each cell and averaged them across neighborhoodswhich in our study are represented by 2012 census block groups (CBGs). ${ }^{3}$ Using 2012 CBGs has two advantages. First, 2012 CBGs precisely correspond with the 2012 satellite imagery. Second, CBGs are reasonable approximations of urban neighborhoods, particularly in scale. Most people can traverse an urban CBG by walking. Thus, people living in a CBG are likely within walking distance of any significant patch of green space (although they might not necessarily see the greenery by peering out their windows). We argue that CBGs are more reasonable approximations of neighborhoods than are census tracts or zip codes - which have been used in other national studies of greenspace.

\footnotetext{
3 Since many urban neighborhoods contain bodies of water - which is, like vegetation, soothing and valuable - our calculations do not include cells that contain water since they would lower the mean NDVI score. In addition to calculating the mean NDVI score of cells within each CBG, we also determined the proportion of raster cells within a CBG that had an NDVI score above various thresholds. This is an indication of the proportion of a CBG area that is covered in dense greenery. For example, we observed the proportion of raster cells within a CBG that were above 3,000. Using these thresholds did not produce substantively different results than using the mean value of NDVI within CBGs. For the sake of parsimony, we use one measure of verdancy in our statistical analysis.
} 
A CBG containing a mix of residential neighborhoods, parks with dense tree cover, grass-covered playgrounds, tree-lined streets, cemeteries, golf courses, and the like will typically have a mean NDVI cell value between 1,000 and 3,000 (with values greater than 3,000 indicating a CBG with large swaths of dense greenery). Scores hovering around zero may have some grass and trees, while scores less than $-1,000$ will typically consist of residential areas with very little greenery.

These scores will, of course, vary across the country. For example, a CBG in Seattle that contains a sizable, tree-covered park will have a higher NDVI score than, say, a similar-sized CBG in Chicago with a sizable, tree-covered park (and, overall, Chicago will be more verdant than Phoenix or Las Vegas). National variation in NDVI did not affect our analysis for two reasons. First, we compared group differences in exposure to green space. Second, we did this within cities. Our approach assessed whether white people are surrounded by more (or less) green space than African American or Hispanic people in the same city. As we discuss more extensively below, our unit of analysis was a city-and we compared groups within a city. It is not an issue if, say, white people in Seattle are surrounded by more verdancy than white people in Phoenix. The issue is whether white people in Seattle fair better than people of color in Seattle.

We integrated CBG data of greenery with CBG-level 2012 American Community Survey data describing the racial and economic characteristics of people. We determined the number of people by race within each CBG. The racial categories we analyzed were non-Hispanic white, non-Hispanic African American, Hispanic, and non-white. To measure the economic characteristics of people we used poverty status - an ordinal variable consisting of the following seven categories: 0 to 50 percent of poverty, 51 to 100 percent of poverty, 101 to 125,126 to 150,151 to 185,186 to 200 , greater than $200 .{ }^{4}$

\section{Creating city-level measures for racial groups}

We integrated NDVI data with 2012 American Community Survey data to create city-level variables for our analysis. The dependent variables in our analysis were differences in exposure to verdancy between racial groups or among economic groups within a city. Creating these measures requires several steps. To measure racial differences in exposure to verdancy, we first created exposure to the mean NDVI scores for each racial group by city. We did this by multiplying the number of people of a given racial group (e.g., non-Hispanic white) within a CBG by the CBG's mean NDVI score, giving us a weighted NDVI score for each CBG. For each city, we then summed the weighted NDVI scores

4 For 2012 , a family of four with earnings of $\$ 23,050$ or less was beneath the poverty line. We also examined educational status. Results were substantively similar to those for poverty status. 
and divided the sum by the total number of people in a given racial group. This resulted in average exposure to green space for each racial group within a city. We then took the difference in exposure to green space for pairs of racial groups. Specifically, we subtracted African American exposure from white exposure and Hispanic exposure from white exposure. (We also compared white and non-white exposure.) Higher positive values indicate that the typical white person is exposed to greater amounts of green space compared with the typical African American, Hispanic person, or person of color. Negative values indicate that non-white people have greater exposure to green space than white people.

In our analysis of racial differences to exposure, our main independent variable was racial segregation across CBGs within cities. Because we measured segregation between pairs of racial groups, we used the index of dissimilarity. The formula for the index of dissimilarity is:

$$
D=\left(\frac{1}{2} \sum_{i=1}^{n}\left|\frac{x_{i}}{X}-\frac{y_{i}}{Y}\right|\right) 100
$$

Where $\mathrm{x}_{\mathrm{i}}$ and $\mathrm{y}_{\mathrm{i}}$ are the number of people of racial group $\mathrm{x}$ and $\mathrm{y}$ in CBG $\mathrm{i}$; $\mathrm{X}$ and $\mathrm{Y}$ represent the total number of people of these racial groups in the city. Values of dissimilarity range from 0 to 100. A value of 0 represents perfect integration. This arises when the proportion of people of each racial group are the same for each neighborhood and the entire city. For example, if 65 percent of the people in a city are white and 35 percent are African American, each neighborhood within a city would have the same 65/35 racial composition. A value of 100 represents complete segregation (i.e., each of the two racial groups live in completely different CBGs).

\section{Creating city-level measures of segregation for economic groups}

The dependent variable for economic groups is the association between exposure to green space and poverty status. This measure is created in several steps. As with racial groups, we first calculated exposure to green space for each of the seven categories of poverty. We did this by multiplying the number of people in a poverty classification (e.g., people less than half of the poverty threshold, people between half and 100 percent of the poverty threshold, and so on) within a CBG by the CBG's mean NDVI score. This resulted in a weighted NDVI score for each $C B G$ and each poverty classification. For each city, we summed the weighted NDVI scores and divided the sum by the total number of people of a given poverty classification. This resulted in average exposure to green space for each poverty classification within a city. 
For each city, we then measured the association between each group's poverty classification and their exposure to greenness. We treated poverty classification as an interval variable in which zero represented the lowest category of poverty and six the highest. We calculated a regression coefficient (i.e., the slope) between poverty classification and exposure to green space for each of the poverty groups. These slopes are a way to summarize differences in exposure to verdancy among multiple income classifications. If there is no association between poverty classification and exposure to green space (i.e., the slope is zero), then different poverty groups are, on average, exposed to equal amounts of green space in their neighborhoods. Positive, higher coefficients (i.e., steeper slopes) indicate that a city's higher-income people are, on average, exposed to greater amounts of verdancy than its lower-income people.

After calculating our dependent variable, we calculated an ordinal measure of segregation - the ordinal entropy index - to determine the spatial distribution of poverty groups across a city (Reardon, 2009). Ordinal entropy (HO) measures the extent to which higher-income groups are spatially segregated from lower ones. Unlike most segregation indices that rely on nominal categories, $\mathrm{HO}$ is based on the cumulative proportion of people below a given poverty level. It is calculated as follows:

$$
H O=\sum_{i=1}^{i} \frac{t_{i}}{T} * \frac{v-v_{i}}{v}
$$

where $\mathrm{T}$ is the total population in a city and $t_{i}$ is the population in CBG $\mathrm{i}$. Here $v$ and $v_{i}$ are the values of entropy for the city and each CBG within the city, respectively. The value $\mathrm{v}$ is calculated as follows:

$$
v=-\frac{1}{M-1} \sum_{m=1}^{M-1} c_{m} \log _{2} c_{m}+\left(1-c_{m}\right) \log _{2}\left(1-c_{m}\right)
$$

where $M$ represents the number of poverty groups, $m$ represents ordered poverty categories and, as shown below, $\mathrm{c}_{\mathrm{m}}$ is the cumulative proportion (p) of a city's population in poverty groups $\mathrm{k}$ that are less than and equal to each poverty category $\mathrm{m}$ :

$$
c_{m}=\sum_{k=1}^{m} p_{k}
$$


Note that $\mathrm{c}_{\mathrm{m}}$ is not calculated for the highest poverty group since it equals 1 ; also, following Reardon (2009), zero to the log of base 2 is treated as zero. Once entropy for the city is calculated for cumulative poverty shares it is necessary to calculate entropy for each CBG (as indexed by i):

$$
v_{i}=-\frac{1}{M-1} \sum_{m=1}^{M-1} c_{i m} \log _{2} c_{i m}+\left(1-c_{i m}\right) \log _{2}\left(1-c_{i m}\right)
$$

Values of $\mathrm{HO}$ range from 0 to 100 (we multiplied HO by 100 for ease of interpretation). When $\mathrm{HO}$ is 100 , each poverty group is located in CBGs that have no other poverty groups within them; thus, these ordered poverty groups are completely segregated from one another. When HO equals zero the proportion of people in all poverty classifications in every CBG is the same as the proportion of poverty groups for the city as a whole.

In addition to measures of racial and economic segregation, we also included several control variables. These included a city's population size and population density-measured by the number of people per square mile of land area. We also included the proportion of each city's population that was African American or Hispanic.

Since segregation is more meaningful in cities with many neighborhoods and a mix of racial groups, we assessed cities with seven or more CBGs. We also analyzed larger cities since it is impossible to reach the maximum level of economic segregation among the seven poverty groups unless there are at least seven CBGs. The final data set we analyzed contained 1,528 cities, all of which contained more than 25,000 people.

We used ordinary least squares regression to determine whether racial segregation increases the disparities in exposure to verdancy between white people and African American people (or white people and Hispanics). We also used ordinary least squares regression to determine whether disparities in green space among economic groups grow as economic segregation increases. Linear regression models were weighted by each city's population ${ }^{5}$ and robust standard errors based on the Huber/White Sandwich estimates are reported (Huber, 1967; White, 1980). We analyzed four dependent variables: disparities in green space

5 To test for robustness of our results, we ran linear mixed regression models in which a state-level random effect was included to adjust for within-state correlations among cities from the same state. These models produced results substantively similar to linear models and, for the sake of simplicity, we report the regular regression results here. We also ran non-weighted regression models (in which each city was not weighted by its population). These results were nearly identical to those with population weights. Results are available upon request. 
between (1) white and African American people, (2) white and Hispanic people, (3) white and non-white people, and (4) among poverty classifications. The most important covariates are the various segregation measures described above.

\section{Results}

Table 1 shows basic descriptive statistics for the exposure to green space for African American, Hispanic and white people. As expected, the average city dweller (regardless of their race) lives in a CBG with little green space. This is indicated by the negative values for mean exposure to green space among all racial groups, which can be seen in the first three rows of Table 1. These low values can be interpreted to mean that most people live in a CBG dominated by cells with little to no vegetation. Still, this basic finding has some nuance. First, some cities have people who live in CBGs with a great deal of green space - as indicated by the maximum score for exposure to green space that is over 3,000. For example, the city with highest mean exposure to green space is Westport, Connecticut, which has mean exposure to green space of 2,928 for African American people, 3,035 for Hispanic people and 3,144 for white people. The typical Westport resident lives in a CBG in which much of the landscape is verdant. Half of Westport's CBGs have mean NDVI scores above 3,000 (and many of the areas within these CBGs have NDVI scores above 5,000). Still, most urbanites reside within CBGs with little green space.

Table 1. Characteristics of cities with more than 25,000 people

\begin{tabular}{|l|c|c|c|c|}
\hline Contact with green space & Mean & $\begin{array}{c}\text { Standard } \\
\text { deviation }\end{array}$ & Minimum & Maximum \\
\hline African American & -890 & 1,578 & $-5,064$ & 3,070 \\
\hline Hispanic & -906 & 1,588 & $-5,081$ & 3,035 \\
\hline Non-white & -878 & 1,581 & $-5,067$ & 3,068 \\
\hline White & -639 & 1,638 & $-5,012$ & 3,144 \\
\hline African American/white difference & 251 & 331 & $-1,286$ & 2,341 \\
\hline White/Hispanic difference & 267 & 321 & -678 & 2,475 \\
\hline White/non-white difference & 239 & 288 & $-1,015$ & 2,353 \\
\hline 0-50\% of poverty & -785 & 1,606 & $-5,008$ & 3,168 \\
\hline 51-100\% of poverty & -795 & 1,611 & $-5,027$ & 2,994 \\
\hline 101-125\% of poverty & -768 & 1,618 & $-4,969$ & 3,302 \\
\hline 126-150\% of poverty & -748 & 1,625 & $-5,049$ & 3,213 \\
\hline 151-185\% of poverty & -727 & 1,627 & $-5,017$ & 3,152 \\
\hline 186-200\% of poverty & -706 & 1,635 & $-5,029$ & 3,087 \\
\hline Greater than 200\% of poverty & -580 & 1,659 & $-5,004$ & 3,095 \\
\hline
\end{tabular}




\begin{tabular}{|l|c|c|c|c|}
\hline Contact with green space & Mean & $\begin{array}{c}\text { Standard } \\
\text { deviation }\end{array}$ & Minimum & Maximum \\
\hline Slope of poverty & 46 & \multicolumn{1}{|c|}{58} & -180 & \multicolumn{1}{c|}{393} \\
\hline African American/white dissimilarity & \multicolumn{1}{|c|}{36} & \multicolumn{1}{c|}{13} & 8 & 84 \\
\hline White/Hispanic dissimilarity & \multicolumn{1}{|c|}{29} & \multicolumn{1}{c|}{12} & \multicolumn{1}{c|}{3} & \multicolumn{1}{c|}{75} \\
\hline Poverty segregation (HO) & .12 & .04 & .02 & .32 \\
\hline Population (10,000s) & 9.31 & 27.15 & 2.50 & 817.06 \\
\hline People per square mile (1,000s) & 3.63 & 3.59 & .05 & 51.76 \\
\hline Percent African American & 12.68 & 15.99 & .09 & 96.94 \\
\hline Percent Hispanic & 19.72 & 20.19 & .51 & 97.45 \\
\hline
\end{tabular}

Despite the relative lack of vegetation in the typical person's CBG, the typical white person lives in a CBG with higher average NDVI scores than the typical African American or Hispanic person. These mean differences appear to be modest-about 267 between white and Hispanic people, 251 between white and African American people, and 239 between white and non-white people. Still, in some cities, the difference in mean NDVI scores is substantial. For example, Menlo Park, California, has a difference in NDVI scores between white and African American people of nearly 2,341. The difference between white and Hispanic people is 2,109.

Similar patterns are found among poverty groups - people with greater income are exposed to more green space. In particular, people whose income is greater than twice the poverty threshold live in CBGs with NDVI indices that are slightly over 300 points higher than people who are at less than 50 percent of the poverty line. For example, in Tallahassee, Florida, the typical person whose poverty status is less than half of the poverty threshold lives in a CBG with a mean NDVI value of 1,000 . By contrast, a person who lives in a family that earns more than twice the poverty threshold lives in a CBG with an average NDVI score of about 2,000 - a very substantial difference.

Although our findings are consistent with previous literature (Wen et al., 2013), our main question is whether racial and economic segregation in cities is associated with racial and economic differences in exposure to greenery. In some cities, segregation between white and African American people is quite lowas is segregation among poverty groups. For example, Vancouver, Washington, has an African American/white dissimilarity score of 0.20. Given that many members of these two racial groups live in many of the same neighborhoods, the typical white or African American person is exposed to the same amount of green space. By contrast, in a highly segregated city such as Chicago - which has an African American/white dissimilarity score of 0.84 - there may or may not 
be differences in exposure to green space among racial groups. It is conceivable that in racially segregated cities people of color and white people live in different neighborhoods but are surrounded by the same amounts of verdancy.

Indeed, the regression analyses indicate that there are relatively strong correlations between racial disparities in exposure to green space and racial segregation. Specifically, for every 1-point increase in racial segregation in a city, the African American/white difference in exposure to green space increases by nearly eight points; this can be seen in Model 1 of Table 2. While this may not seem large, in a city that is extremely segregated (e.g., one with a dissimilarity score of 80), African American/white differences in average NDVI scores will be, on average, 600 points. Still, as indicated by an explained variance of 0.09 , there is considerable variation in exposure to green space between African American and white people and segregation across cities. Nevertheless, of the 47 cities in which there is a 1,000-point African American/white difference in NDVI values, in 38 (or 80 percent) of them, white people live in much more verdant CBGs than African American people.

Table 2. Regressions of racial differences in exposure to green space

\begin{tabular}{|c|c|c|c|c|c|c|}
\hline \multirow[b]{2}{*}{ African American/white differences } & \multicolumn{3}{|c|}{ Model 1} & \multicolumn{3}{|c|}{ Model 2} \\
\hline & $b$ & se & $\beta$ & $b$ & se & $\beta$ \\
\hline Dissimilarity African American/white & $7.9^{\star \star}$ & 1.1 & .39 & $7.9^{\star \star}$ & 1.4 & .29 \\
\hline Poverty segregation $(\mathrm{HO})$ & & & & $9.7^{\star *}$ & 2.6 & .12 \\
\hline Population (1,000s) & & & & $-4.0^{*}$ & 1.2 & -.05 \\
\hline People per square mile $(1,000 \mathrm{~s})$ & & & & -3.4 & 3.6 & -.03 \\
\hline Percent African American & & & & -1.7 & .8 & -.08 \\
\hline Percent Hispanic & & & & -.9 & .5 & -.05 \\
\hline Constant & -20.8 & 32.6 & & -65.7 & 37.5 & \\
\hline R-squared & .09 & & & .11 & & \\
\hline Hispanic/white differences & $b$ & se & $\beta$ & $b$ & se & $\beta$ \\
\hline Dissimilarity Hispanic/white & $14.1^{\star *}$ & 1.0 & .52 & $15.7^{\star *}$ & 1.2 & .58 \\
\hline Poverty segregation $(\mathrm{HO})$ & & & & 0.2 & 2.6 & .00 \\
\hline Population (1,000s) & & & & $-3.6^{*}$ & 1.1 & -.05 \\
\hline People per square mile $(1,000 \mathrm{~s})$ & & & & 4.0 & 3.6 & .04 \\
\hline Percent African American & & & & $-2.5^{\star \star}$ & .7 & -.13 \\
\hline Percent Hispanic & & & & $-2.0^{\star *}$ & .4 & -.12 \\
\hline Constant & $-128.1^{\star *}$ & 23.0 & & $-104.8^{\star *}$ & 31.0 & \\
\hline R-squared & .27 & & & .29 & & \\
\hline
\end{tabular}




\begin{tabular}{|l|c|c|c|c|c|c|}
\hline & \multicolumn{3}{|c|}{ Model 1 } & \multicolumn{3}{c|}{ Model 2 } \\
\hline Non-white/white differences & $\boldsymbol{b}$ & se & $\boldsymbol{\beta}$ & $\boldsymbol{b}$ & \multicolumn{1}{c|}{ se } & \multicolumn{1}{c|}{$\boldsymbol{\beta}$} \\
\hline Dissimilarity non-white/white & $8.8^{\star \star}$ & .98 & .35 & $10.0^{\star \star}$ & 1.1 & .41 \\
\hline Poverty segregation (HO) & & & & $6.7^{\star \star}$ & 2.3 & .10 \\
\hline Population (1,000s) & & & & $-3.6^{\star \star}$ & 1.1 & -.06 \\
\hline People per square mile (1,000s) & & & & 4.1 & 3.4 & .05 \\
\hline Percent African American & & & & $-3.2^{\star \star}$ & .9 & -.18 \\
\hline Percent Hispanic & & & & $-.97^{\star}$ & .4 & \multicolumn{1}{c|}{-.07} \\
\hline Constant & -18.0 & 21.0 & & $-79.0^{\star \star}$ & 30.0 & \\
\hline R-squared & .12 & & & .16 & & \\
\hline
\end{tabular}

Note. ${ }^{*} p=.05 .{ }^{* \star} p=.01$.

To explore factors that may account for African American/white differences in NDVI values, we included several covariates, as shown in Model 2 of Table 2. The inclusion of control variables does not diminish the effects of African American/white segregation. While Model 2 explains slightly more variance than Model 1, results indicate that control variables have little bearing on African American/white differences in NDVI values.

Our exploration of Hispanic/white segregation revealed that it has a strong influence of differences in Hispanic/white NDVI values - about twice as strong as African American/white segregation. Specifically, for every 1-point increase in Hispanic/white dissimilarity, there is a 14-point difference in Hispanic/white NDVI values. In cities that are highly segregated - those with Hispanic/white dissimilarity scores of 75-average differences in NDVI values are 930. In cities such as Birmingham, Alabama, the typical white person lives in a CBG with a mean NDVI value of 1,012 . The comparable value for Hispanic people is -0.63 . This roughly 1,000-point difference in NDVI values is about what one would expect given that Birmingham's white/Hispanic dissimilarity is 58. Several other results suggest the robust nature between segregation and differences in exposure to green space. Explained variance in Model 1 is 0.27 - a fairly high number given that Model 1 incorporated only one covariate. Also, Model 2 incorporated a number of covariates as controls but these had little influence on the coefficient for dissimilarity between Hispanic and white people. ${ }^{6}$

6 For the sake of brevity, we do not discuss non-white/white differences in exposure to green space since the results are quite similar to those between black and white people and between Hispanic and white people. 


\section{Economic segregation and exposure to green space}

The last models explored the association among poverty groups' exposure to green space and economic segregation. Again, we found fairly strong correlations. As Model 1 of Table 3 shows, there is a 5-point increase in the association between poverty category and NDVI scores for every 1-point increase in segregation among poverty groups. Since the measures themselves are a bit complicated, it is useful to provide examples that represent these associations. Meadow Woods, Florida, is a city with low segregation among poverty groups $(\mathrm{HO}=0.07)$ and there is little association between poverty status and neighborhood NDVI scores (i.e., the slope between poverty classification and CBG NDVI values is 8). In essence, all poverty groups live in CBGs with the same amount of green space - and that is largely because they are not segregated. Specific NDVI values for Meadow Woods's poverty groups are shown in Table 4.

Table 3. Regressions of economic differences in exposure to green space

\begin{tabular}{|l|c|c|c|c|c|c|}
\hline & \multicolumn{3}{|c|}{ Model 1 } & \multicolumn{3}{c|}{ Model 2 } \\
\hline & $b$ & Se & B & $b$ & Se & $\beta$ \\
\hline Dissimilarity Hispanic/white & & & & .06 & .16 & .01 \\
\hline Dissimilarity African American/white & & & & $.99^{\star *}$ & .18 & .19 \\
\hline Poverty segregation (HO) & $5.18^{\star \star}$ & .44 & .37 & $4.01^{\star *}$ & .51 & .28 \\
\hline Population (1,000s) & & & & -.44 & .18 & -.03 \\
\hline People per square mile (1,000s) & & & & .08 & .51 & .00 \\
\hline Percent African American & & & & $-.27^{\star}$ & .10 & -.07 \\
\hline Percent Hispanic & & & & $-.42^{\star \star}$ & .08 & -.14 \\
\hline Constant & $-17.17^{\star \star}$ & 4.84 & & $-19.50^{\star}$ & 6.45 & \\
\hline R-squared & .14 & & & .17 & & \\
\hline
\end{tabular}

Note. ${ }^{*} p=.05 .{ }^{*} p=.01$.

Table 4. Contact with green space among poverty groups

\begin{tabular}{|l|r|r|r|r|r|r|r|r|r|}
\hline City & HO & Slope & $0-0.50$ & $\begin{array}{c}0.51- \\
1.00\end{array}$ & $\begin{array}{c}\mathbf{1 . 0 1 -} \\
\mathbf{1 . 2 5}\end{array}$ & $\begin{array}{c}\mathbf{1 . 2 6 -} \\
\mathbf{1 . 5 0}\end{array}$ & $\begin{array}{c}\mathbf{1 . 5 1 -} \\
\mathbf{1 . 8 5}\end{array}$ & $\begin{array}{c}\mathbf{1 . 8 6 -} \\
\mathbf{2 . 0 0}\end{array}$ & $\mathbf{2 0 0 +}$ \\
\hline Meadow Woods & 0 & 4 & 778 & 803 & 865 & 832 & 797 & 844 & 811 \\
\hline Franklin Town & 18 & 269 & 1428 & 1989 & 1701 & 2245 & 2270 & 3387 & 2814 \\
\hline
\end{tabular}

In contrast to Meadow Woods, Franklin, Massachusetts, has a high level of segregation among poverty groups and there are large differences in exposure to green space between the lowest and highest poverty groups; these differences are reasonably close to the predicted values based on the regression models. 
For example, the difference in NDVI values between the lowest and highest income categories is nearly 2,000-and there is usually an increase in NDVI values between adjacent income categories.

\section{Study limitations}

There are several important limitations with available data, and these limitations restrict the conclusions that can be drawn from our analyses. We used crosssectional data and no robust causal inferences can be made regarding race/ economic segregation and differences in exposure to green space between racial and economic groups. The challenge of endogeneity introduced a number of questions we cannot answer. Do members of different racial and economic groups seek more green space than others? Or do municipalities locate fewer trees, flowers, parks, golf courses, greenways, and the like in neighborhoods with established populations of minorities and lower-income people? Researchers would need to assemble and analyze several decades of quality longitudinal data (probably semi-annually) to unpack the relationships among changes in green space and shifts in racial and economic composition across neighborhoods. This may be possible in the near future as more waves of American Community Survey data become available - along with future waves of national land cover data.

Beyond the question of which came first - the people or the trees - there are related questions regarding the mechanics of how green space is distributed. It may be that more green space exists in neighborhoods with greater shares of white people, but a national-level study cannot determine whether white people and people with higher incomes plant more trees, shrubs, and grass than minorities and lower-income people - or whether more-advantaged people are more likely to demand and obtain green space from their municipal leaders. Such questions are better addressed with studies that can track change over time at a very fine scale and combine qualitative and quantitative data.

There are a few other weaknesses with the data. One is that we do not distinguish between various ethnic groups (e.g., Hispanics who are white or African American). Future studies can provide more detail regarding specific racial groups. Moreover, available data do not allow us to determine the exact proximity of households to greenness. It may be that a New York City penthouse is located across the street from Central Park; still, the use of CBGs as proxies for neighborhoods may indicate that the penthouse is located in a neighborhood with little green space. To determine whether this is the case, researchers would need access to data of residential addresses - data that do not exist nationally. Similarly, it may be possible to use census blocks (rather than block groups) and distribute racial populations over a raster to approximate their residential 
locations. ${ }^{7}$ While such an approach might restrict the number of cities that can be analyzed, it may further validate the basic results we produce here. A final weakness is that satellite imagery does not necessarily capture the quality of vegetation in a neighborhood. Vacant lots overrun with thick weeds and poisonous plants are not the same as well-maintained public parks with walking paths, flowers, and playgrounds. It is not possible to measure the quality of vegetation while conducting a national study; still, we do not simply assume that patches of greenery with the same NDVI values are equally pleasant.

\section{Conclusions and future research}

We found relationships between city-level racial and economic segregation and differences in exposure to green space between the members of different racial and income groups. Such findings indicate how racial and economic segregation affect a person's quality of life with respect to verdancy. The more racially segregated a city is, the more likely it is that people of color will live in neighborhoods with less greenery than their white counterparts. The same patterns hold among poverty groups. These findings yield new information. Green space is not distributed evenly across neighborhoods within cities. Theoretically, this uneven distribution need not inevitably lead to a situation in which one racial or economic group is, on average, exposed to more or less green space than another. But our findings show otherwise. Consistent with much of the literature on racial and economic segregation - and studies of environmental (in)justice - we find that lower-income people and members of minority groups live in neighborhoods with much less vegetation than their wealthier, white counterparts but, on average, these differences are exacerbated in racially and economically segregated cities.

Our analyses do not fully explore the relative importance of racial or economic segregation in predicting exposure to green space. Future research can address this question by examining the relationship between economic segregation and differences to exposure to green space among poverty groups within the same racial group (or racial differences within the same economic group). We suspect that income differences are more powerful than are racial categories - but this is an open question.

7 Counts of people by poverty status or income level are available only at the block group level. 


\section{References}

Adelman, R. (2004). Neighborhood opportunities, race, and class: The black middle class and residential segregation. City \& Community, 3(1), 43-63.

Boone, C., Buckley, G., Grove, M., \& Sister, C. (2009). Parks and people: An environmental justice inquiry in Baltimore, Maryland. Annals of the Association of American Geographers, 99(4), 767-787.

Boone-Heinonen, J., Gordon-Larsen, P., Kiefe, C., Shikany, J., Lewis, C., \& Popkin, B. (2011). Fast food restaurants and food stores: Longitudinal associations with diet in young to middle-aged adults: The CARDIA study. Archives of Internal Medicine, 171(13), 1162-1170.

Bullard, R. (2000). Dumping in Dixie: Race, class, and environmental quality. Boulder, CO: Westview Press.

Chiesura, A. (2004). The role of urban parks for the sustainable city. Landscape and Urban Planning, 68(1), 129-138.

Cradock, A., Kawachi, I., Colditz, G., Hannon, C., Melly, S., Wiecha J., \& Gortmaker, S. (2005). Playground safety and access in Boston neighborhoods. American Journal of Preventive Medicine, 28(4), 357-363.

Crowder, K., \& Downey, L. (2010). Interneighborhood migration, race, and environmental hazards: Modeling microlevel processes of environmental inequality. American Journal of Sociology, 115(4), 1110-1149.

Duncan, D., White, K., Aldstadt, J., Castro, M., Whalen, J., \& Williams, D. (2012). Space, race, and poverty: Spatial inequalities in walkable neighborhood amenities? Demographic Research, 26(17), 409-448.

Goffman, A. (2014). On the run: Fugitive life in an American city. Chicago: University of Chicago Press.

Hansen, M., Potapov, P., Moore, R., Hancher, M., Turubanova, S., Tyukavina, A., Thau, D., Stehman, S., Goetz, S., Loveland, S., Kommareddy, A., Egorov, A., Chini, L., Justice, C., \& Townshend, J. (2013). High-resolution global maps of 21st-century forest cover change. Science, 342(6160), 850-853.

Heckert, M. (2013). Access and equity in greenspace provision: A comparison of methods to assess the impacts of greening vacant land. Transactions in GIS, $17(6), 808-827$.

Heynen, N. (2003). The scalar production of injustice within the urban forest. Antipode, 35(5), 980-998. 
Heynen, N., \& Lindsey, G. (2003). Correlates of urban forest canopy cover: Implications for local public works. Public Works Management \& Policy, $8(1), 33-47$.

Heynen, N., Perkins, H., \& Roy, P. (2006). The political ecology of uneven urban green space: The impact of political economy on race and ethnicity in producing environmental inequality in Milwaukee. Urban Affairs Review, 42(1), 3-25.

Huber, P. J. (1967). The behavior of maximum likelihood estimates under nonstandard conditions. In L. M. Le Cam \& J. Neyman (Eds.), Proceedings of the Fifth Berkeley Symposium on Mathematical Statistics and Probability (pp. 1, 221-233). Berkeley, CA: University of California Press.

Kwate, N. (2008). Fried chicken and fresh apples: Racial segregation as a fundamental cause of fast food density in black neighborhoods. Health \& Place, 14(1), 32-44.

Landry, S., \& Chakraborty, J. (2009). Street trees and equity: Evaluating the spatial distribution of an urban amenity. Environment and Planning A, 41(11), 2651-2670.

Lindsey, G., Maraj, M., \& Kuan, S. (2001). Access, equity, and urban greenways: An exploratory investigation. The Professional Geographer, 53(3), 332-346.

Maas, J., Verheij, R., Groenewegen, P., De Vries, S., \& Spreeuwenberg, P. (2006). Green space, urbanity, and health: How strong is the relation? Journal of Epidemiology and Community Health, 60(7), 587-592.

Maller, C., Townsend, M., Pryor, A., Brown, P., \& St Leger, L. (2006). Healthy nature, healthy people: "Contact with nature" as an upstream health promotion intervention for populations. Health Promotion International, $21(1), 45-54$.

Massey, D., \& Fischer, M. (2000). How segregation concentrates poverty. Ethnic and Racial Studies, 23(4), 670-691.

Mitchell, R., \& Popham, F. (2008). Effect of exposure to natural environment on health inequalities: An observational population study. The Lancet, 372(9650), 1655-1660.

Nielsen, T., \& Hansen, K. (2007). Do green areas affect health? Results from a Danish survey on the use of green areas and health indicators. Health \& Place, 13(4), 839-850. 
Reardon, S. (2009). Measures of ordinal segregation. Research on Economic Inequality, 17(1), 129-155.

Sampson, R. (2012). Great American city: Chicago and the enduring neighborhood effect. Chicago: University of Chicago Press.

Sister, C., Wolch, J., \& Wilson, J. (2010). Got green? Addressing environmental justice in park provision. Geojournal, 75(3), 229-248.

Squires, G., \& O'Connor, S. (1998). Fringe banking in Milwaukee: The rise of check-cashing businesses and the emergence of a two-tiered banking system. Urban Affairs Review, 34(1), 126-149.

Troy, A., Grove, J., O'Neil-Dunne, J., Pickett, S., \& Cadenasso, M. (2007). Predicting opportunities for greening and patterns of vegetation on private urban lands. Environmental Management, 40(3), 394-412.

Ward-Thompson, C., Roe, J., Aspinall, P., Mitchell, R., Clow, A., \& Miller, D. (2012). More green space is linked to less stress in deprived communities: Evidence from salivary cortisol patterns. Landscape and Urban Planning, 105(3), 221-229.

Wen, M., Zhang, X., Harris, C., Holt, J., \& Croft, J. (2013). Spatial disparities in the distribution of parks and green spaces in the USA. Annals of Behavioral Medicine, 45(1), 18-27.

Wendel, H., Downs, J., \& Mihelcic, J. (2011). Assessing equitable access to urban green space: The role of engineered water infrastructure. Environmental Science \& Technology, 45(16), 6728-6734.

White, H. (1980). A heteroskedasticity-consistent covariance matrix estimator and a direct test for heteroskedasticity. Econometrica, 48(4), 817-838.

Wing, S., Cole, D., \& Grant, G. (2000). Environmental injustice in North Carolina's hog industry. Environmental Health Perspectives, 108(3), 225-231.

Wrigley, N., Warm, D., \& Margetts, B. (2003). Deprivation, diet, and foodretail access: Findings from the Leedsfood deserts' study. Environment and Planning A, 35(1), 151-188.

Zenk, S., Schulz, A., Israel, B., James, S., Bao, S., \& Wilson, M. (2005). Neighborhood racial composition, neighborhood poverty, and the spatial accessibility of supermarkets in metropolitan Detroit. American Journal of Public Health, 95(4), 660-667. 
This text is taken from Human Ecology Review, Volume 21, Number 2, 2015, published 2015 by ANU Press, The Australian National University, Canberra, Australia. 